\title{
FISCAL PRESSURE OF HEALTH CARE
}

\author{
B. Madzhurova \\ PhD student, Department "Economic Science", Faculty of Economic and Social Sciences, Plovdiv \\ University "Paisii Hilendarski", Plovdiv, Bulgaria
}

\begin{abstract}
The pressure on public finances of the Health care will continue to be strengthened in two ways: a) the development of newer and more expensive systems for diagnosis and treatment requiring a high-paid medical personnel; b) increased demand for health services from the aging population. In Bulgaria the problem particularly acute because of the declining number of working-age population that landed on the growing fiscal burden on workers and businesses. This is evident by the growing deficits of National health insurance fund, despite an increase in social security contributions by 2 percentage points.

To mitigate the problem of increasing fiscal pressure on the line of the health care are need political decisions on three lines: a) increase in revenues from health insurance contributions by improving the collection and reduce the number of persons without health insurance; b) reform of the health system, particularly expanded hospital sector; c) curbing abuse and fraud with public funds, including through the introduction of the electronic health card.
\end{abstract}

Key words: Fiscal pressure, health care, public finance, political decisions

Increasing long-term costs of the state budget for health care is a subject of concern because of the pressure exerted on public finances. In recent years the focus and the European Union (EU) falls on two parallel questionscost containment while adequate protection from the risk of disease. The economic and financial crisis requires more equitable distribution and responsibilities of the system. The pressure on public finances of the Health care will continue to be strengthened in two ways: a) the development of newer and more expensive systems for diagnosis and treatment requiring a high-paid medical personnel; b) increased demand for health services from the aging population.

Modeling the financial structure of the health sector means dealing with the most complex part of social protection. While in pension and other cash benefits system, the economic and demographic environment, as well as their legal rules, almost fully define their financial developments, health system face the additional complexity of patient-provider relationship in less than perfect markets, as well as often unpredictable morbidity structure.

\section{HEALTH EXPENDITURES}

Public expenditure includes government spending (central and local budgets), external loans and grants (including donations from international agencies and non-governmental organizations), as well as funds for compulsory health insurance. Components of private spending are direct payments to households, private insurance, charitable donations and direct payments by private corporations.

A key objective in Bulgaria it has to ensure sustainability of the public finances, including in a long-term perspective. Fiscal sustainability refers to the ability to continue now and in the future current policies (with no changes regarding public services and taxation) without causing public debt to rise continuously as a share of GDP. In 2014 the European Union EU 28 the health expenditure as a share of GDP is $8.7 \%$., Bulgaria- $7.6 \%$ of GDP. All health cost spending on health care (excluding long-term nursing care) absorbs a significant and growing share of resources. 


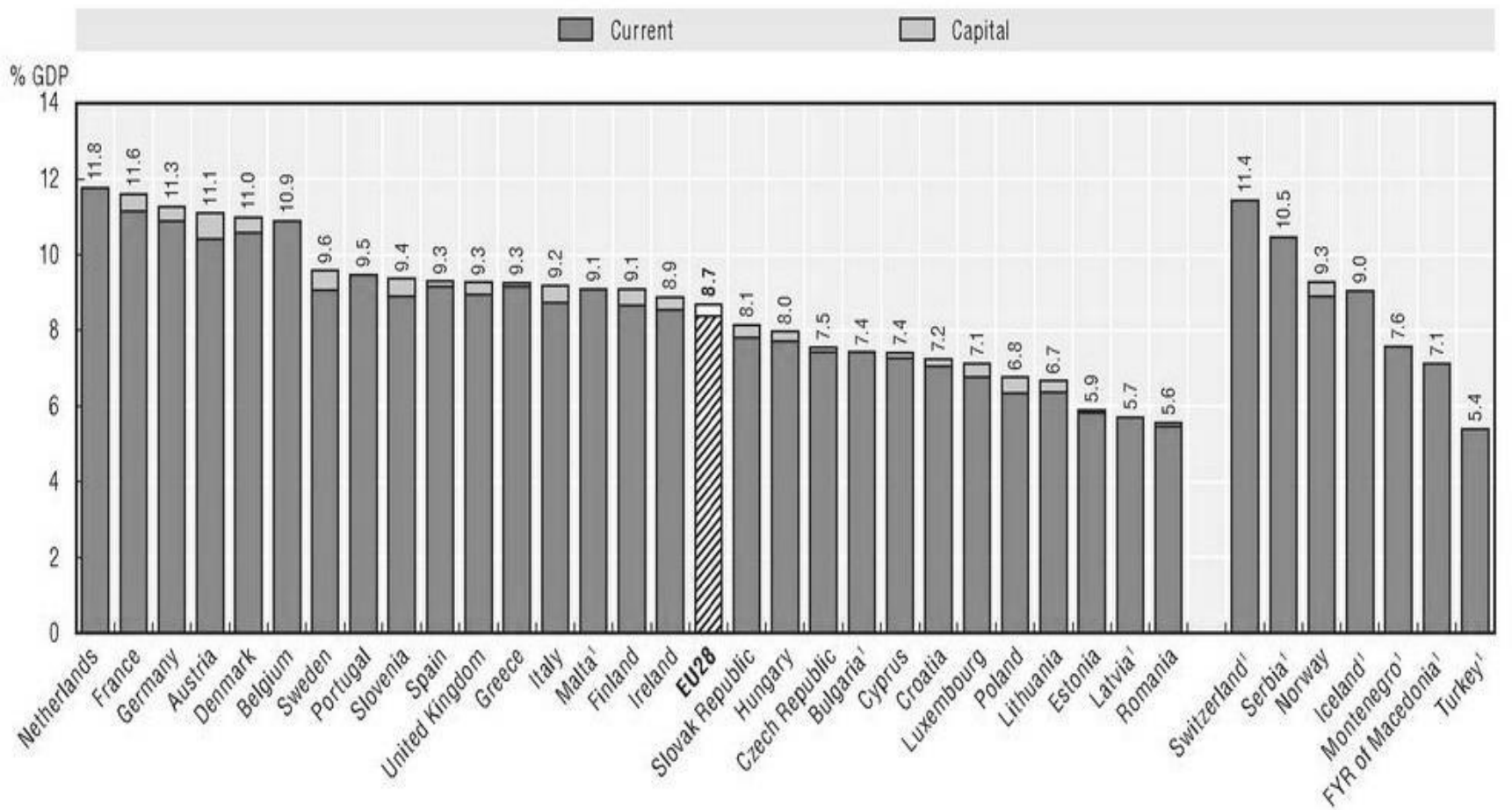

1. Total expenditure only (no breakdown between current and capital spending available).

Source: OECD Health Statistics 2014, http://dx.doi.org/10.1787/health-data-en; Eurostat Statistics Database; WHO Global Health Expenditure Database.

Figure 1. Health expenditure as a share if $\mathrm{GDP}^{1}$

Source: OECD Health Statistic 2014, Health at a Glance 2014

Current (2011) and projected (2011-2060) public expenditure on health

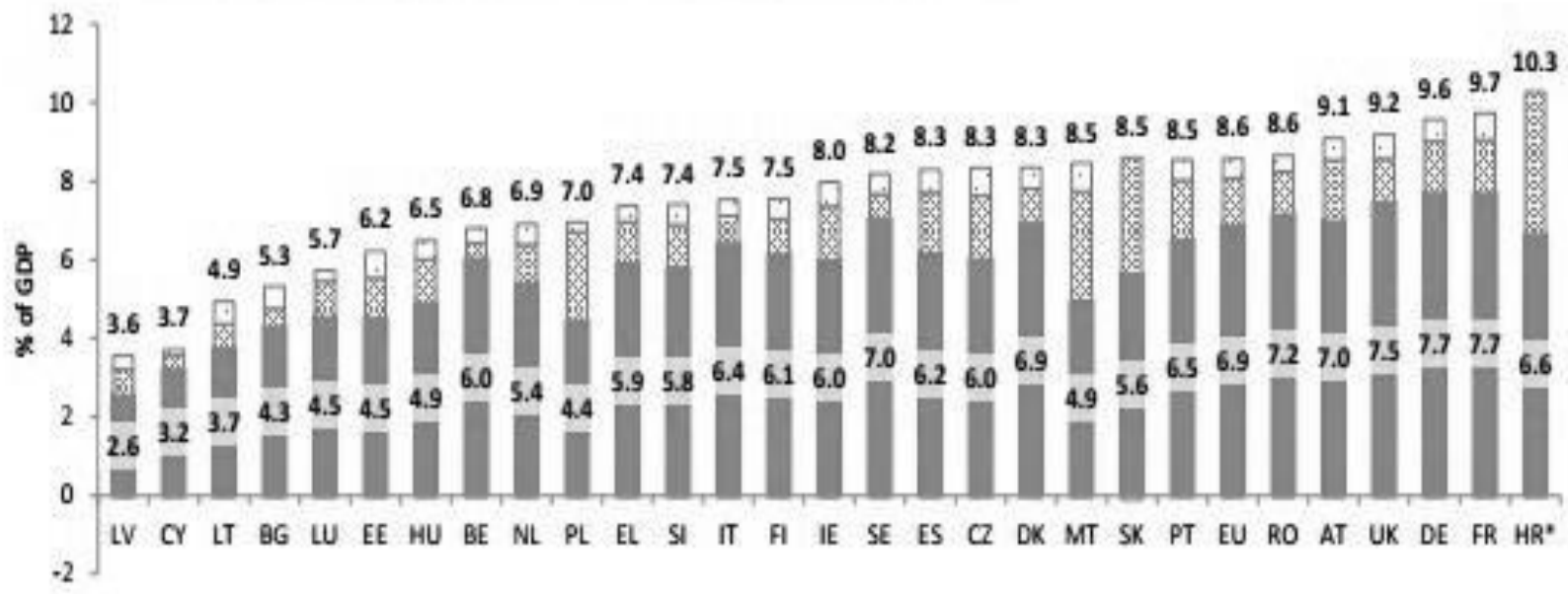

\section{E2011, actual or projected $\quad \square 2011$-2060 (AWG reference scenario) $\quad \square 2011$ - 2060 (AWG risk scenario)}

Soun:2012 Ageing Report, Fiscal Sustainability Report 2012, European Commission, own calculations.

Notes: The ranking of the countries deviates from the ranking in the Ageing Report, as the 2011 data has been updated for some countries acoording to data availability. Data for Croatia includes the projection of long-term care spending based on national sources, as no separate projection for health care and long-term care is available. No risk scenario is available for HR either.

Data excludes spending for long-term nursing care (HC.s category of the system of health accounts).

Figure 2. Current and projected (2011-2060) public expenditure on health ${ }^{2}$

\footnotetext{
${ }^{1}$ Source: OECD Health Statistic 2014, Health at a Glance 2014

${ }^{2}$ Source: European Commission, 2012 Ageing Report, Fiscal Sustainability Report 2012

Trakia Journal of Sciences, Vol. 13, Suppl. 1, 2015
} 
The growing importance of public expenditure on health care as a share of GDP and in total government expenditure and the need for budgetary consolidation all across the European Union has brought public expenditure on health care into the spotlight within the policy debate on how to ensure the medium- and long-term sustainability of public finances.

In Bulgaria in 2014 the public expenditure on health as share of GDP is $4.2 \%$ in comparison with the EU of $7.3 \%$.

Public expenditure on health as share of GDP

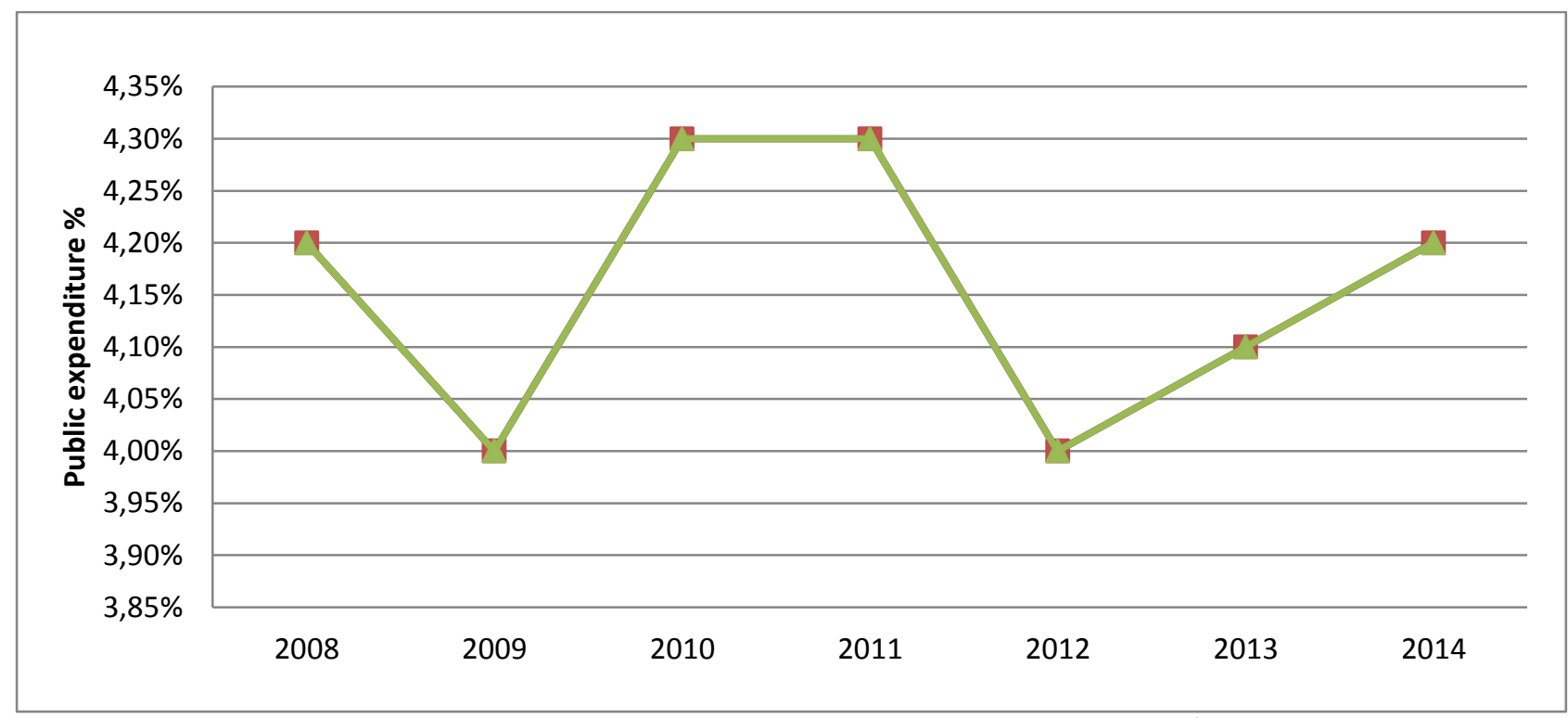

Chart 1. Public expenditure on health as share of GDP ${ }^{3}$

In the last 10 years, the structure of revenues for system has changed significantly. The state withdrew consistently from healthcare financing. In Bulgaria in 2014, public health expenditure is $59.3 \%$ of total health expenditure, EU- 77.3\%. On the graph is the public health expenditure of total health expenditure in compare with the European Union.

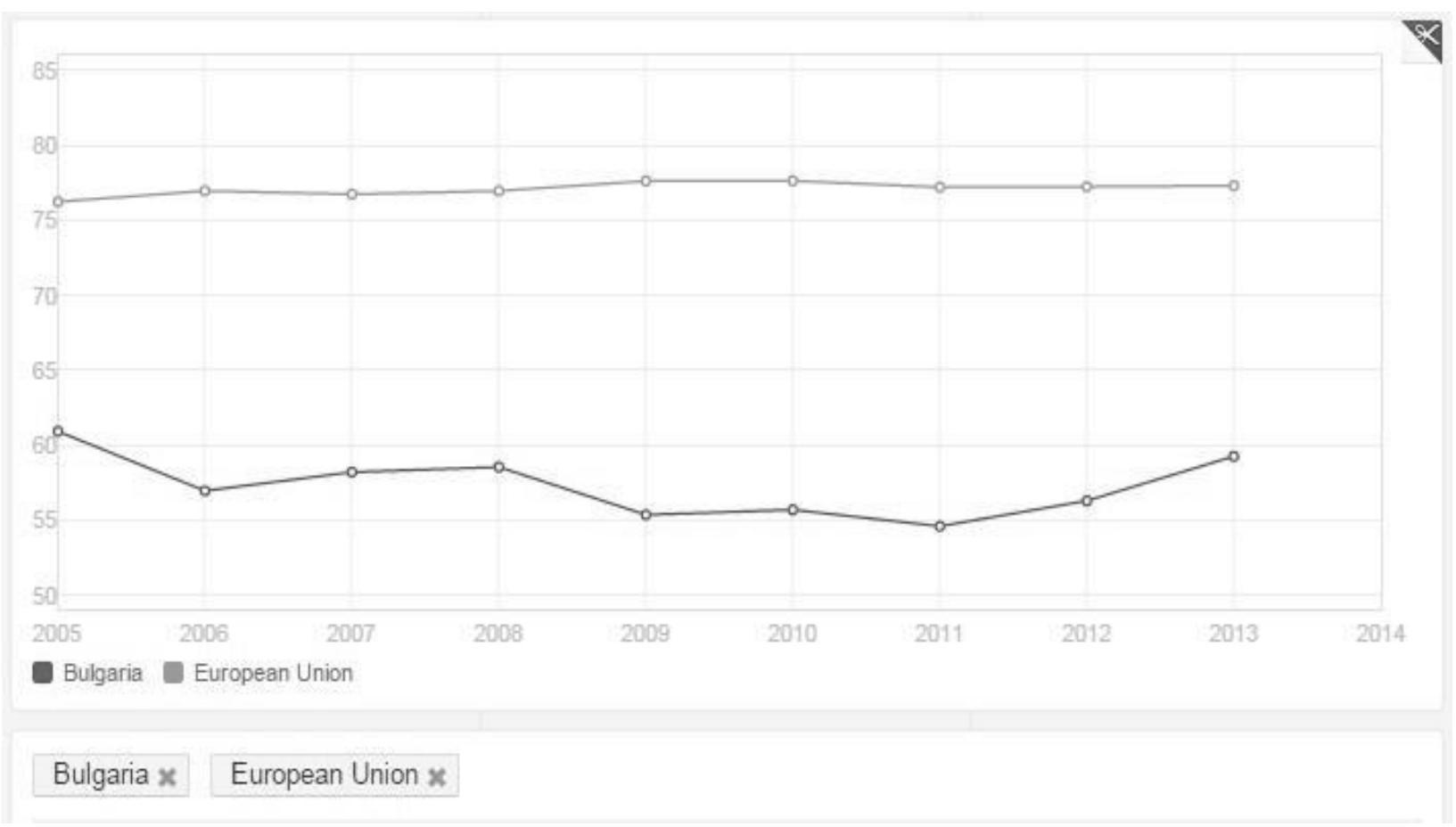

Figure 3. Public health expenditure of total health expenditure in compare Bulgaria and the EU ${ }^{4}$ Source: World Bank

\footnotetext{
${ }^{3}$ Source: Own graphic

${ }^{4}$ Source: World Bank
} 


\section{FISCAL PRESSURE \\ INCOMES}

In the health sector in Bulgaria there is only one institution that collects mandatory health insurance and dispose of them - the National Health Insurance Fund (NHIF). This effectively means that there is a state monopoly sectors, despite the presence of private hospitals, hospitals and health insurance funds. Significant deficiency in the NHIF budget for 2013-2014 clearly suggests the existence of problems in the system. A big part part of the costs of the Ministry of Health have been redirected for payment by the
NHIF budget, without the corresponding changes in the Fund's budget. The costs of prevention, prevention, promotion and control of public health gradually are transferred to the budget of the NHIF. This is evident by the growing deficits of National health insurance fund, despite an increase in social security contributions by 2 percentage points. The incomes of the budget of the NHIF in 2014 formed $65 \%$ of contributions and $35 \%$ of transfers of the State budget. The share of the NHIF budget in total health expenditure increased by $60 \%$ - in 2008 to $81 \%$ in 2014 .

Incomes of the budget of the NHIF (social security contributions; state budget)

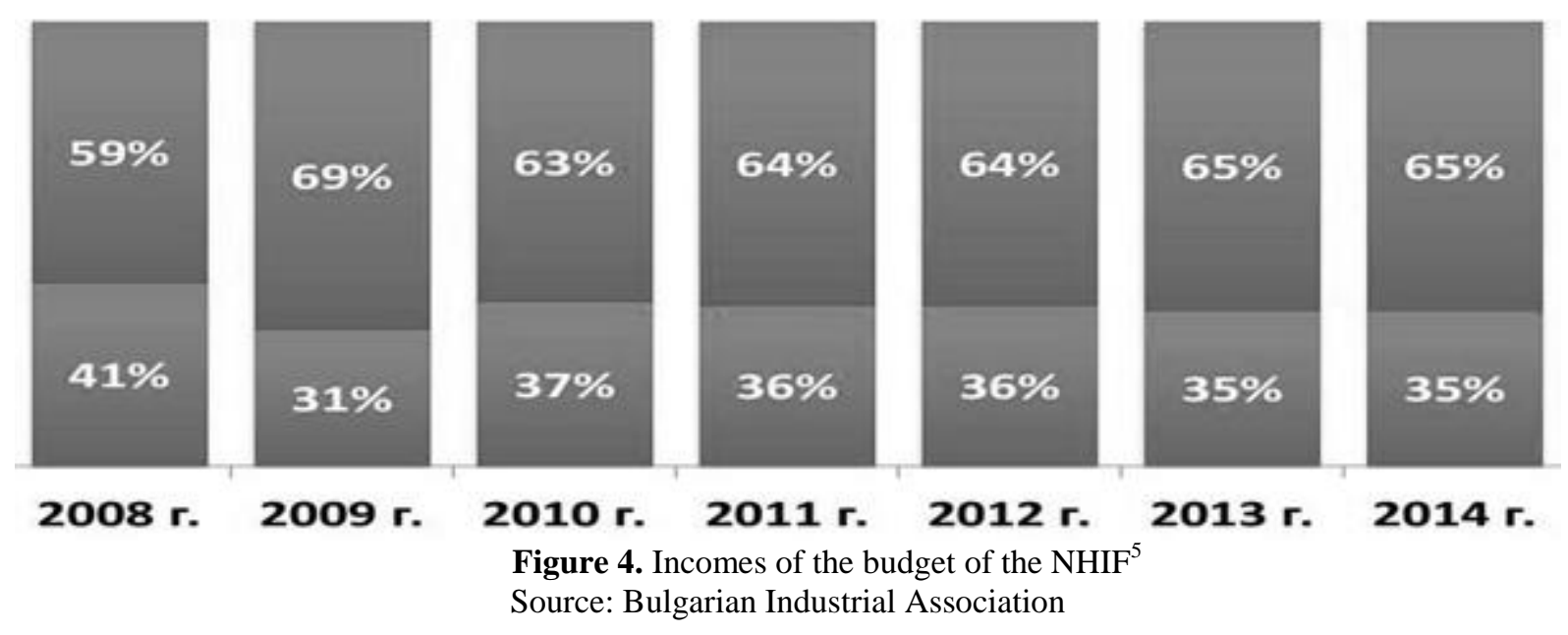

\section{FISSCAL PRESSURE- NON DEMOGRAPHIC FACTOR}

Income is another key determinant of health costs (Gerdtham and Jönsson, 2000). A priori, it is unclear whether health expenditure is an inferior, a normal or a superior good, i.e. it is the income elasticity of health demand lower, equal or higher than one? As in the EU a high share of health expenditure is covered by public health insurance schemes, the individual income elasticity of demand is low. At the same time, increases in insurance coverage have strengthened the link between national income and aggregate demand for health services, through the implicit softening of budgetary constraints. In fact, income elasticity tends to increase with the level of aggregation of the data, implying that health expenditure could be both "an individual necessity and a national luxury" (Getzen, 2000). Maisonneuve and Martins (2006) suggest that the high income elasticities (above one) often found in macro studies may result from the failure to control for price and

${ }^{5}$ Source: Bulgarian Industrial Association quality effects in econometric analysis. More recent studies, tackling some methodological drawbacks of previous ones (e.g. related to omitted variables and/or endogeneity bias), estimate income elasticities of health demand of around one or below (Azizi et al., 2005; Acemoglu et al. 2009).

In the past decades, health expenditure has been growing much faster than what would be expected from changes in demography and income. Many studies claim that the gap is filled by technologic advances in the health sector. Innovations in medical technology allow for expanding health care to previously untreated medical conditions and are believed to be a major driver of health expenditure. Smith et al. (2009) suggest that between $27 \%$ to $48 \%$ of health expenditure since 1960 is explained by innovations in medical technology. Earlier studies estimated that about $50 \%$ to $75 \%$ of increases in total expenditure were driven by technology (Newhouse, 1992; Cutler, 1995; Okunade and Murthy, 2002; and Maisonneuve and Martins, 2006). Cutler (2004) argues that technological advances in medical sciences have generated 
both far-reaching advances in longevity and a rapid rise in costs. Chandra and Skinner (2011) attempt to better understand the links between technological progress in health and its impact on costs and the effectiveness of treatments. They rank general categories of treatments according to their contribution to health productivity, defined as the improvement in health outcome per cost.

In Bulgaria of a long-term investment policy is delayd. Much of the hospitals do not have the modern equipment and personnel for quality and timely diagnosis and treatment. No government policy and transparent criteria when buying high-tech machines and equipment and health technologies with public funds. No consistent policy with medical staff. Deepen deformation in the structure, number and territorial distribution of specialists in different fields.

Another important dimension of public health expenditure is the regulatory settings and policies on the provision and financing of health care. Regulations may set budgetary constraints, define the extent of public health coverage, and provide behavioral rules and incentives for providers and payers aimed at the financial or medical quality of outcomes. In our country is very common is the change of regulations related to health issues and health insurance. There is no legal framework for the terms and conditions of payment by the patients of the underlying medical services for them . There are legal provisions in the Health Insurance Act, which contribute to wiredraw the NHIF.

At the time is no legal instrument with which to define clear rules on procedure and manner of care of persons without health insurance and the financing of this activity. The problem with the status of hospitals is not solved.

In Bulgaria besides the above factors of fiscal pressures that some of them occur in Europe, there are specific ones. There is inefficient operation of the revenue administration, which does not collect mandatory health insurance of over 1.2 million. people. Contributions for persons insured by the State do not meet the actual cost. Unreasonably large number of hospitals - an oversupply medical services and activities concentrated in big cities. Also in the European Union public expenditure on hospitals represents a very large share of total public expenditure on health care (on average more than 40\%) and has not changed significantly in the past decade despite calls for policy reform that moves healt care from hospital to primary and community settings. In below are some of the problems that we can observe in Bulgaria. The dimensions of corruption in health care are very high. The effectiveness of control is low. The control activity is registration, no precaution and not reported the effect and results of the medical service. There is no political solution to the problems of privatization in health care. A factor for improving the efficiency and transparency of the system and the quality and control of medical services is the introduction of ehealth, but it is delayed. Still we do not have a government policies and concrete actions to reduce the number of persons without health insurance. There is no long-term strategy for emergency medical help. The management of the NHIF does not match the public nature of the institution.

Prevention is declared as a key priority, but it was not provided with the necessary financial resources, organization and a strict regulatory framework, incl. penalties for violators. Do not place the necessary dialogue to consolidate society to conduct health care reform. The health system is very bureaucratic, leading to the involvement of large resources to administer the activities of the NHIF, the Ministry of Health and agencies to it. It was not built horizontal links NHIF with the Social Security funds. We have not measured the effect on the quality of medical care on cost optimization of social funds. The state did not intervened cardinal changes in the order and control the way in granting disability pensions for sickness. There are still problems with the growing amount of benefits for temporary disability.

\section{DEALING WITH FISCAL PRESSURE}

To mitigate the problem of increasing fiscal pressure on the line of the health care are need political decisions on three lines:

a) Increase in revenues from health insurance contributions by improving the collection and reduce the number of persons without health insurance. There is an urgent decision that must be taken for health uninsured persons in the whole chain - identification, registration, medical care.

The introduction of two packages and pricing of the basic package of health services guaranteed by the NHIF budget will reduce the fiscal pressure.

b) Reform of the health system, particularly expanded hospital sector. Cost of NHIF funding of the hospital sector has increased since 2008 until today with $44 \%$, and it is 
excessive concentrated funds in several cities and several hospitals. Highly is expanded the hospital sector. For dealing with this problem we must introduce the electronic health card. We need to develop a long-term strategy for emergency aid, and reduce administrative costs.

c) Curbing abuse and fraud with public funds. It is necessary to prepare a roadmap to change the health status of the population and to implement a new approach to control activities on the basis of computerization of the management.

The Ageing Report 2012, Fiscal Sustainability Report 2012, for the purposes of establishing whether on the basis of current policies a large adjustment in policy is required to ensure fiscal sustainability, we look at the sustainability indicators (the S1 and S2 indicators) used in budgetary surveillance in the EU. This multidimensional approach enables assessing:

- medium-term challenges, through fiscal gaps related to the excess of projected expenditure, including age-related expenditure (notably on pensions, health care and long-term care) over projected revenue together with any gap with respect to the primary balance needed to bring the debt-to-GDP ratio to $60 \%$ of GDP by 2030 (S1 indicator). This indicator, therefore, takes into account age-related spending trends over the medium term and beyond, influenced by among others country-specific demographic prospects and country-specific arrangements of pension systems. Moreover and importantly, it incorporates the effort needed by high-debt countries to respect the Treaty threshold of $60 \%$ of GDP for government debt within a reasonable time span.

- long-term challenges, through fiscal gaps related to the excess of projected expenditure, including age-related expenditure (specifically on pension, health care and long-term care) over projected revenue together with any gap with respect to the primary balance needed to ensure that the debt-to-GDP ratio is not on an ever-increasing path (S2 indicator). This indicator, therefore, takes into account very long-term trends, which is highly relevant when analysing public spending programmes like pensions and health care.

Countries with high $\mathrm{S} 1$ or $\mathrm{S} 2$ values are classified to be at medium risk ( $\mathrm{S} 1$ higher than zero or S2 higher than 2) and high risk (S1 higher than 2.5 or $\mathrm{S} 2$ higher than 6). For Bulgaria S1 (2014-2030) is -1.2 and S2 (2014-2060) is 3.4. At medium-term challenges Bulgaria is not a risk country but in long term we can observe a medium risk. ${ }^{6}$

Governments care both about the health status of populations and budget sustainability. There is no doubt that healthier populations are important for thriving economies. Bulgaria could get better value for money from their health care spending.

Health care spending indeed needs to become more effective. Otherwise, health care demand will undermine public finances. The recent crisis and its impact on public budgets have heightened pressures for reform and made it more urgent.

A key objective in the EU and as pat is to ensure sustainability of the public finances, including in a long-term perspective. Fiscal sustainability refers to the ability to continue now and in the future current policies (with no changes regarding public services and taxation) without causing public debt to rise continuously as a share of GDP.

\section{REFERENCES}

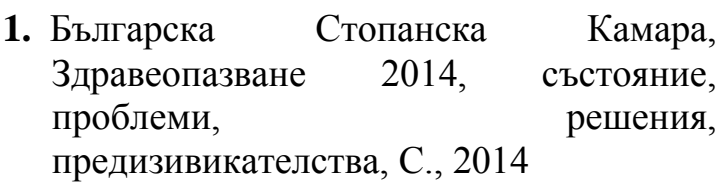

2. Министерство на здравеопазването, Нормативни актове и документи, Проекти на закони

3. Национална Здравноосигурителна каса, Отчети на НЗОК, Годишен отчет за дейността 2014

4. Неева, М., Системата на здравеопазване в българия в числа и графики, Институт за пазарна икономика, С.,2014

5. European Commission, DirectorateGeneral for Economic and Financial Affairs, Public finances in EMU, pp 147192, Brussels, 2013.

6. European Commission, DirectorateGeneral for Economic and Financial Affairs, Identifying fiscal sustainability challenges in the areas of pension, health care and long-term care policies, Brussels, 2014.

7. Eurostat. Expenditure of selected health care functions by providers of health care EUR, national currency and PPS

8. Health at a Glance 2013: OECD Indicators, OECD Publishing, Paris, 2013

9. Health at a Glance 2014: OECD Indicators, OECD Publishing, Paris, 2014

\footnotetext{
${ }^{6}$ Identifying fiscal sustainability challenges in the areas of pension, health care and long-term care policies, Document of European Commission
} 
10.Health at a Glance 2014: Europe 2014, joint publication of the OECD and the European Commission, OECD Publishing, Paris, 2014

11.OECD 2010, "Health care systems: Getting more value for money", OECD Economics Department Policy Notes, No. 2.

12.OECD. Stats Extracts, http://stats.oecd.org/index.aspx?DataSetCo de=HEALTH_STAT\#
13.Publications Office of the European Union, EU Budget 2013, Financial Report, Luxembourg, 2014

14.Wolfgang, Sch., Cichon , M., Hagemejer, Krz., Social Budgeting. International Labor Office, Geneva, Switzerland, 2000.

15.World Bank. Databank. World Health Organization Global Health Expenditure database 